\title{
EDUCAÇÃO DO CORPO DE SUJEITOS ESCOLARES: UM ESTUDO EM PERSPECTIVA PÓS-ESTRUTURALISTA
}

\author{
Odiléia do Socorro Ribeiro RODRIGUES \\ Campus Universitário de Abactetuba/UFPA \\ odileia24@yahoo.com.br
}

\begin{abstract}
Resumo: O presente texto apresenta resultados proliminares de imestigasāo. Toma cono objeto de estrudo a produçāo discursiva do corpo de sujertos en contexto escolas $e$ objeriva examinar dispositivos de escolarizasão e sua incidência sobre o corpo. $O$ campo empírico da pesquisa constifui-se de escolas urbanas no municipio de Abnetenba/PA. O estudo adoton cono subsina teśrico-metodológico, a análise do discurso a problenatizaçāo sobre os modos de subjetüngâo e a constiturição do sujeito sob a perspectina foncaultiana. A partir desta perspectiva, anuncia-se que o processo de subjetinaşão em contexto escolar perpassa pela adogāo de dispositivos discursivos de normalização, de disciplinarizaşầ, disposirines de governo de si e dos ontros. Tais dispositions se materializam no contexwo escolar por meio de Regimentos, registros en Linns de Ororkincia, carrazes contativos de práticas morais e disciplinares, enire outros.
\end{abstract}

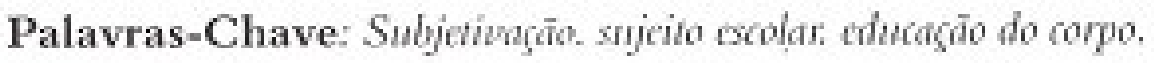

Abstract: The presen ext shous preliminary rosults of investigation. It like as objective of strdy the discursine production of the body of subjets in schoolship context and goals examine devins of shooling and your incidence over the body. The

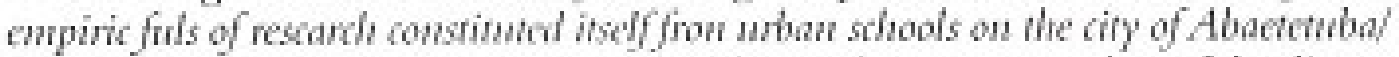
PA. The study adoped a theorical-nethodologic substract, an analyse of the discuss and the problenalizarion over the ways of subjetivity and the corstiturion of subject under the perspective of Fouraht. Starting fron the perspective it anounces that the process of strbjetivity in shoolship context to pass by the adoption of discursive devias of normalized, of disciplining gowern devian of itself and the ohers. Those devian matcralize in schoolship context by the Reginien, register in Books of Occurrence, eschonative posters of moral and distiplinary practices anony orhers.

Keywords: subjetivity. schoolship subject. body education.

1 Discente do Curso de Pedagogia da Universidade Federal do Para, Campus Universitário de Abactetuba e Bolsista PIBIC-INTERIOR/UFPA. Desenvolvet stua investigaçio, em 2007, no interior do Projeto de Pesquisa "Educaçäo e subjetivaçio: a produçäo de sujeitos em contexto escolar", e desenvolve atualmente o estudo Érica e estética de si: a hernenétutica do stujeile en Midhel Foucault, sob a Orientaçâo do Prof. M.Sc. Jadson Fernando Garcia Gonçalves. 


\section{Introdução}

A pesquisa em andamento ora apresentada intenciona flagrar, por meio de processo investigativo, quais os modos de produção discursiva do corpo de sujeitos escolares dialogando com produçôes de pesquisa em educaçâo de vertente pós-estruturalista, mais especificamente aquelas baseadas nos trabalhos de Nietzsche, Foucault, Deleuze, porém mais precisamente no campo de estudo do discurso e dos modos de subjetivação sob a perspectiva foucaultina.

Ou seja, o presente estudo volta-se para a compreensão daquilo que a instituição escolar está fazendo com os sujeitos escolares a fim de constituí-los como sujeitos de determinados tipos, e, correlativamente, compreender o que fazem os escolares com aquilo que a escola quer que eles sejam. Neste movimento escola/sujeito/escola, nosso objetivo ć fundamentalmente identificar, analisar e compreender as diversas estratégias utilizadas no contexto escolar como estratégias ou práticas de subjetivação, entendidas como "[...] injunçōes, conselhos, técnicas, pequenos hábitos de pensamento $\mathrm{c}$ emoção, uma série de rotinas e normas do ser humano - os instrumentos por meio dos quais [c através dos quais] o ser humano constitui a si próprio em diferentes práticas $\mathrm{e}$ relaçōes" (ROSE, 2001, p. 51).

A problematizaçã̃o deste trabalho está voltada para o sujeito, foco central dos escritos foucaultianos. E ć precisamente isto que justifica a escolha dos escritos de Foucault como referencial teórico-metodológico, na medida em que nos permite argumentar que um exercício de estranhamento, de afastamento c de interrogação sobre aquilo que somos ou pensamos ser pode se constituir analiticamente em algo produtivo, ao nos "mostrar" que tudo aquilo que nos parece o mais evidente, o mais natural das coisas, seus modos de funcionamento, suas regras, suas normas, que em grande medida determinam nossos modos de pensar, nossos comportamentos e condutas, pode e deve ser questionado.

$\hat{E}$ neste sentido que pretendemos problematizar as práticas discursivas escolares como campos de saber imersos $\mathrm{cm}$ relaçōes de poder, como práticas de subjetivação e, no caso específico do contexto escolar, como local privilegiado de construção de subjetividades onde cstão presentes "práticas regulares [...] modificadas sem cessar através da história" (FOUCAULT, 2003, p. 11), agenciamentos coletivos de produção/reprodução de disciplinamentos, normas, privilegiamento de saberes, relaçốes de poder, lutas, disposição dos corpos, resistências... 
Tramas complexas que se materializam por meio de práticas discursivas $\mathrm{cm}$ meio a lutas políticas de significação.

Atentar para o papel que os discursos desempenham no processo de constituição da realidade é estar destacando os efeitos de verdade na produção de subjetividades, ou seja, é estar afirmando que as subjetividades são também resultados de operações discursivas. Daí a necessidade de investigarmos de que modo tais operaçōes são engendradas e colocadas em funcionamento no contexto escolar.

\section{Os encaminhamentos investigativos}

No que se diz respeito aos aspectos metodológicos, cumpre destacar que a atenção está voltada para a obtenção de materiais e dispositivos escolares que mantém relação direta ou indireta com o processo de controle, disciplina e gestão de sujeitos escolares. Assim, consideramos como fontes documentais na composição do corpus empírico: regimentos, cartazes, avisos livretos, registro de ocorrências e qualquer material que apresente vestígios de conduta ética, moral e disciplinar que incida sobre os corpos de sujeitos escolares. Também é objeto de atenção a disposição espacial e arquitetural da escola e sua funçīo de disciplinamento do espaço escolar (FOUCAULT, 2004a).

A pesquisa se desenvolve $\mathrm{cm}$ escolas urbanas no município de Abaetetuba. Foram incluídas no estudo cscolas públicas que ofertam o ensino fundamental de $5^{a}$. a $8^{\mathrm{a}}$, série e que atendam a um número expressivo de discentes. Após a definição das escolas, procedemos à coleta dos materiais e dispositivos acima enunciados. Neste momento foi possível nos apropriarmos de cópias de Regimentos Internos das escolas e de cópias de Livros de Ocorrências, bem como do registro, por meio de fotografias, de clementos da arquitetura da escola.

Em um segundo momento da pesquisa, em que se procura examinar de que modo os sujeitos se apropriam, internalizam ou resistem aos processos de subjetivaçĩo escolares, pretendemos nos valer das narrativas dos próprios sujeitos escolares no sentido de percebermos os processos de constituição de si mesmo ou práticas de si que o sujeito submete a si mesmo ao aceitar ou recusar práticas de determinados tipos, neste caso, práticas escolares. O que se pretende com o recurso às narrativas é ampliar o leque de campo de interrogativas e análise das práticas de si (FOUCAULT, 2004b). 
Apesar desta delimitação metodológica prévia, estamos atentos as fato de que o próprio processo de pesquisa é fluido e incerto. De possc dos materiais, documentos e informaçōes se procederá à análise propriamente dita e, neste aspecto, utilizaremos a análise de discurso de perspectiva foucaultiana, identificando inicialmente as regularidades discursivas, ou seja, os temas recorrentes nos discursos capturados por meio dos materiais, documentos $\mathrm{e}$ informaçōes dos alunos que produzem corpos e mente escolares. Nāo se pretende fazer separaçāo rígida entre o momento da coleta de dados e a análise, mas sempre que possível estar conjugando estes dois momentos.

\section{Os vestígios investigativos preliminares}

O desenvolvimento deste estudo nos tem permitido compreender os processos, mecanismos e discursos que a escola utiliza no sentido de constituir sujeitos sociais de um tipo particular, para atender determinados interesses socioculturais historicamente situados. Daí a intensificação de nosso interesse $\mathrm{cm}$ examinar que tipo de sujeito é esse c que estratégias discursivas são utilizadas neste processo de constituição dos corpos e mentes de sujeitos escolares, direcionadas no sentido de atender determinados projetos de sociedade politicamente orientados. $\mathrm{O}$ contato com as leituras, que de diferentes modos abordam a problemática da construção do corpo, e com o contexto empírico, fez-nos perceber o quanto o espaço escolar opera na construçấo de sujeitos, de subjetividades, a partir de práticas sociais, disciplinares e morais, que, sendo usadas como recursos disciplinares, acabam por incidir e moldar corpos, modos de ser e de agir dos indivíduos. Isto evidencia a dimensão do poder da escola no controle das regularidades e das permanências dos rituais escolares e sua incidência nos corpos.

Quando a escola lança mão do uso do poder, apropria-se do disciplinamento como prática pedagógica efetiva $\mathrm{c}$ controla. Desse modo, "tão raro podemos encontrar alguém que pense por si mesmo" (BELTRĀO, 2000, p. 65). Então o produto da escola, ì primcira vista, é um sujeito que age, que é moldado a partir dos interesses dos outros, da vontade dos outros, do governo dos outros, ou melhor, fala a partir da vontade, do interesse e do governo da escola.

Com cstrutura escolar e disciplinar montadas e com os individuos à sua disposição "uma individualidade começa a ser fabricada" (BELTRÃo, 2(MM), p. 43). Os corpos estāo sujcitos à obediência das ordens, ou melhor, 
ele interioriza e codifica o que tem que ser feito e submete-se a isso. As distribuiçōes feitas no espaço escolar, bem como a prática constante dessas distribuiçōes vāo dando forma aos individuos, vāo fabricando corpos, vão educando-os para serem sujeitos da relaçāo de poder exercido sobre eles. Nesse jogo analítico, em que a fabricaşão é feita a partir da diferença, onde o melhor é aquele que se sujeita, cabe ressaltar que esse sujeito também é o mais silenciado.

Tal compreensão ocorre porque o caráter assumido pela escola é de cunho normalístico, o que contribui para um desenvolvimento sistemático de padrôes, normas e regras que organizam, que determinam a vida, as atividades, o modo de ser, de igir, pensar e praticar de uma forma tăo naturalizada que chega a ser notado que o que está se fazendo na escola é nada mais que cumprir horários, estudar assuntos impostos, resolver exercícios ou fazer alguma atividade apontada por alguém. É nesse interim que nasce o que a escola define como "bom" e "mal".

$O$ bom aluno é o que cumpre com as normas estabelecidas, ajuda c coopera para o comprimento delas e deixa seus valores e comportamentos serem moldados. Ao falarmos em construçio ou produção de corpos, esta é feita pela aplicação de poder e saber sobre os indivíduos, mas não somente sobre estes; tal produção também incide sobre instituições com concep̧̧óes específicas, como a escola, por exemplo. Deste modo, a relaçã̃o de poder-saber explica quem é quem dentro do contexto escolar, bem como da definição de quem obedece. Os regimentos escolares, os cartazes, os informativos expostos em quadros de avisos e murais são alertas prévios de que alguém, naquele espaço, faz uso do poder, respeitado pelos próprios documentos, e alguém que por ventura violar algum desses acordos estabelecidos sofrerá puniçōes. Isso quer nos dizer que o sujeito escolar imprime as regras e depois submete-se a elas.

Quando a escola tenta a qualquer custo manter o controle excessivo, as regras limitadoras passam a ser um grande risco de que o processo de intimidaçāo, de repressão de vontade c de descjo possa ser, com o passar dos tempos, catarseadas de forma considerada irregular, fazendo com que a instituiçāo use de seu poder de controle e penalidades para punir; para fazer a aplicação dos conhecidos castigos. Entāo vemos que a estrutura disciplinar forma e produz sujeitos escolares segundo as suas perspectivas, ou melhor, quando é montada uma estrutura de normas e regras é porque clas apontam para um sentido contrário: o da transgressão. Os alunos tidos como "maus" fazem a negação da disciplina. O problema é que a escola não vê na transgressão um momento de construçẫo, mas sim de reforço 
na intenção de propagar sua estrutura de poder e sua autoridade de punir. As ordens são feitas para serem cumpridas, o rompimento com as normas cstabelecidas acarreta um julgamento, uma aplicaçăo de puniçắo.

Neste sentido, as escolas utilizam as palavras liberdade, democracia, respeitoe disciplina, de modo consciente, para camuflar o uso dos dispositivos de disciplinamento. E esta narrativa precisa ser questionada, problematizada. Deleuze (1992. p. 220) alerta-nos para a seguinte questão: de que "Não se deve perguntar qual é o regime mais duro, ou o mais tolerável, pois é em cada um deles que se enfrentam as liberaçōes e as sujeiçōes".

Os que transgridem essas normas e regras comuns do contexto escolar acabam sempre recebendo um olhar e um tratamento diferenciado. Por tentarem romper o "sagrado", com a manutençāo do igual, são expulsos. As ferramentas usadas para o controle vão se tornando cada vez mais eficientes. Agora, ao contrário dos tempos passados, a aplicação năo é de castigos ou da exposiçã̃o, ela ocorre por intermédio da vigilância mútua. Os nossos movimentos são vistos de forma diferenciada, a nossa limitaçāo de ser e fazer diferente acabam por criar em nós uma pseudoautonomia, pois somos manipulados e controlados pelas opiniōes e regras de conduta. Não somos autônomos $\mathrm{cm}$ gerenciar o nosso "cu". A vida e os fatos contidianos baseiam-se numa prática constante de relaçĩo de poder. No caso da escola não é diferente, cla acaba exercendo a funşāo a que foi designada, que é usar o poder para o controle dos individuos e isso, conseqüentemente, dará uma certa estabilidade para transformar as regras e as normas $\mathrm{cm}$ inscriçōes visiveis na construção dos corpos dos indivíduos e até na construçấo de saberes. Neste caso, a disciplina regula ao nosso interior, a nossa subjetividade.

A elaboração de um discurso de produçāo de corpos com características institucionais é visível quando percebemos que estes são produzidos para atender às exigências do poder; são corpos que falam através de suas estruturas físicas. Gestos, marcas, comportamentos que indicam, definem como os corpos sāo moldados, construídos a partir do exercício do poder delegado pelas diversas instituiçōes sociais. A maneira como é formada, estabelecida e praticada as relaçōes de poder acabam construindo corpos com características expressivas dos efeitos dessa relação. As manifestações corpóreas, discursivas, sã́o capazes de dar a identificaşão sobre a intensidade ou não do uso do poder e do controle exercido sobre o corpo. Dependendo da intensidade cotidiana do poder "xercido sobre os corpos, define-se o jeito de ser e de agir, constituem-se subjetividades. 


\section{Conclusão}

Buscar no espaço escolar indicios e dispositivos que fazem parte do processo de subjetivação dos sujeitos escolares c como eles incidem nos corpos, bem como a concep̧̧ão de sujeito que a escola almeja construir por meio desses dispositivos é ter que se apropriar de procedimentos, mecanismos e instrumentos utilizados nas práticas discursivas pedagógicas que evidenciem regras de conduta e de controle do outro e de si mesmo, em que se possa analisar que o espaço de "ação disciplinadora, arbitrária, e capaz de transformar o corpo $\mathrm{cm}$ produto, passivo de qualquer atitude autônoma" (BELTRÃO, 2000, p. 69). As práticas influenciadoras da produçăo dos corpos, das subjetividades, dos indivíduos no espaço escolar sāo resultantes de influências históricas de diferentes concepçōes filosófico-pedagógicas, as quais se consolidaram como verdade $\mathrm{cm}$ meio a relaçōes de poder.

\section{REFERÊNCIAS}

BELTRĀO, I, R. Corpos dóceis, mentes vazias, coraçōes frios: didática - o discurso científico do disciplinamento. São Paulo: Editora Imaginário, 2000.

DELEUZE, G. Conversaçốes, 1972-1990. Rio de Janciro: Editora 34, 1992.

FOUCAULT, M. A verdade e as Formas Jurídicas. Rio de Janeiro: NAU editora, 2003. Vozes, 2004a.

Vigiar e punir: história da violência nas prisões. Petrópolis:

A hermenêutica do sujeito. Sã̃o Paulo: Martins Fontes, $2004 \mathrm{~b}$.

ROSE, N. Inventando nossos cus, In: SILVA, T, T. da (Org.). Nunca Fomos Humanos: nos rastros do sujeito. Belo Horizonte: Autêntica, 2001, p. 137-204.

Artigo recebido no dia 30 de julho de 2008 e aprovado no dia 02 de setembro de 2008. 